Lermi (2021)

Title Page

\title{
Comparative Molecular Genomic Analyses of a Spontaneous Rhesus Macaque Model of
}

\section{Mismatch Repair-Deficient Colorectal Cancer}

Authors: Nejla Ozirmak Lermi ${ }^{1,6}$, Stanton B. Gray ${ }^{4}$, Charles M. Bowen ${ }^{1}$, Laura Reyes-Uribe ${ }^{1}$, Beth K. Dray ${ }^{8}$, Nan Deng ${ }^{1}$, R. Alan Harris ${ }^{7}$, Muthuswamy Raveendran ${ }^{7}$, Fernando Benavides ${ }^{2}$, Carolyn L. Hodo $^{4}$, Melissa W. Taggart ${ }^{3}$, Karen Colbert Maresso ${ }^{1}$, Krishna M. Sinha ${ }^{1}$, Jeffrey Rogers ${ }^{7}$, and Eduardo Vilar ${ }^{1,5^{*}}$

Affiliations: Departments of ${ }^{1}$ Clinical Cancer Prevention, ${ }^{2}$ Epigenetics and Molecular Carcinogenesis, ${ }^{3}$ Pathology; ${ }^{4}$ Comparative Medicine and Michale E. Keeling Center for Comparative Medicine and Research; ${ }^{5}$ Clinical Cancer Genetics Program; ${ }^{6}$ School of Health Professions, The University of Texas MD Anderson Cancer Center, Houston, TX; ${ }^{7}$ Human Genome Sequencing Center and Department of Molecular and Human Genetics, Baylor College of Medicine, Houston, TX; ${ }^{8}$ Charles River Laboratories, Ashland, $\mathrm{OH}$.

Running Title: Comparative Genomic Analysis of Colorectal Cancers in Rhesus

*Corresponding Author: Eduardo Vilar, MD, PhD, Clinical Cancer Prevention - Unit 1360, The University of Texas MD Anderson Cancer Center, PO Box 301439, Houston, TX 77230-1439; P: (713) 745-4929; F: (713) 794-4403; E-mail: EVilar@mdanderson.org Abbreviations: CRC, colorectal cancer; CSC, cancer stem cell; Colorectal adenocarcinoma, COAD; DEGs, differentially expressed genes; FAP, familial adenomatous polyposis; GSEA, gene set enrichment analysis; H\&E, hematoxylin and eosin; Het, heterozygous; IHC, immunohistochemistry; LS, Lynch 
Lermi (2021)

26 Syndrome; MMRd, mismatch repair-deficient; MMRp, MMR-proficient; NES, normalized enrichment

27 score; RNAseq, RNA sequencing; MDACC, The University of Texas MD Anderson Cancer Center; The

28 Cancer Genome Atlas, TCGA; READ, rectal adenocarcinoma.

\section{Declarations}

31 All animal experiments were conducted in compliance with the National Institutes of Health guidelines

32 for animal research and approved by MDACC Institutional Animal Care and Use Committee (IACUC,

33 Protocol \#0804-RN02).

Availability of data and materials: Data are available upon reasonable requests directed to the corresponding author. (See Corresponding Author section, above).

37

Conflict of Interest Disclosures: Dr. Vilar has a consulting or advisory role with Janssen Research and

Development and Recursion Pharma. He has received research support from Janssen Research and

Development.

42 Funding/Support: This work was supported by a gift from the Feinberg Family Foundation and

43 MDACC Institutional Research Grant (IRG) Program to E.V.; MD Anderson Internal Grant Award from

44 Cattlemen for Cancer Research to S.G.; R24 OD011173 (US National Institutes of Health) to J.R.; and 45 CA016672 (US National Institutes of Health/National Cancer Institute) to The University of Texas MD 46 Anderson Cancer Center Core Support Grant.

48 Manuscript (without Figure Legends and References): 5409

Abstract: 205

50 Number of references: 41 
bioRxiv preprint doi: https://doi.org/10.1101/2021.08.19.456691; this version posted August 19, 2021. The copyright holder for this preprint (which was not certified by peer review) is the author/funder, who has granted bioRxiv a license to display the preprint in perpetuity. It is made available under aCC-BY-NC-ND 4.0 International license.

Lermi (2021)

\section{Number of Figures: 5}

52 Number of Supplementary Figures and Tables: 7 Figures, 3 Tables 
Lermi (2021)

53

54

55

56

57

58

59

60

61

62

63

64

65

66

67

68

69

70

71

72

\section{Abstract}

Colorectal cancer (CRC) remains the third most common cancer in the US with $15 \%$ of cases displaying Microsatellite Instability (MSI) secondary to Lynch Syndrome (LS) or somatic hypermethylation of the MLH1 promoter. A cohort of rhesus macaques from our institution developed spontaneous mismatch repair deficient (MMRd) CRC with a notable fraction harboring a pathogenic germline mutation in $M L H I$ (c.1029C<G, p.Tyr343Ter). Our study incorporated a detailed molecular characterization of rhesus CRC for cross-comparison with human MMRd CRC. We performed PCR-based MSI testing, transcriptomic analysis, and reduced-representation bisulfite sequencing (RRBS) of rhesus $\mathrm{CRC}(\mathrm{n}=41$ samples) using next-generation sequencing (NGS). Systems biology pipelines were used for gene set enrichment analysis (GSEA) for pathway discovery, consensus molecular subtyping (CMS), and somatic mutation profiling. Overall, the majority of rhesus tumors displayed high levels of MSI (MSI-high) and differential gene expression profiles that were consistent with known deregulated pathways in human CRC. DNA methylation analysis exposed differentially methylated patterns among MSI-H, MSI-L (MSI-low)/MSS (MS-stable) and LS tumors with MLH1 predominantly inactivated among sporadic MSI-H CRCs. The findings from this study support the use of rhesus macaques as the preferred animal model to study carcinogenesis, develop immunotherapies and vaccines, and implement chemoprevention approaches pertinent to sporadic MSI-H and LS CRC in humans.

1 Keywords: Rhesus macaque, Colorectal cancer, Lynch syndrome, Microsatellite instability, Nextgeneration sequencing, Bioinformatics, Epigenetics 
Lermi (2021)

\section{Introduction}

Colorectal cancer $(\mathrm{CRC})$ remains the third leading cause of cancer-related deaths affecting both men and women (1). Approximately $15 \%$ of CRC cases display microsatellite instability (MSI) secondary to a defective mismatch repair (MMRd) system that is recognized as a major carcinogenic pathway for CRC development. MMRd arises as a result of either (1) an inherited germline mutation in one of four genes (MLH1, MSH2, MSH6 and PMS2) constituting the MMR system followed by an acquired second-hit in the wild-type allele of the same gene in colonic mucosa cells (i.e., Lynch syndrome) or (2) somatic inactivation of the $M L H 1$ gene (i.e., MSI sporadic CRC).

A better understanding of colorectal neoplasia arising in the setting of MSI/MMRd is urgently needed to tailor the use of early detection, prevention, and treatment interventions in this subset of CRC, including established immunotherapies and the development of novel immuno-preventive regimens. Such interventions are particularly needed for those with Lynch syndrome, as they are at the highest risk of CRC as well as a range of other cancers. Unfortunately, no concrete model with higher translational value exists to study the nuanced carcinogenesis of MMRd CRC, which is a critical barrier for studying this subset of CRC and, consequently, to making advances in its detection, prevention, and treatment.

Presently, in vitro and ex vivo models, such as cell lines and organoids respectively, are commonly used to study CRC; however, the intrinsic nature of these models lack cellular heterogeneity and fail to recapitulate the tumor microenvironment (TME) observed in-vivo (2). To combat the limitations of invitro/ex-vivo cultures, mouse models (Mus musculus) have been leveraged to study CRC prevention, initiation, and progression. Although murine models of genetic inactivation of MMR genes exist, these models drastically diverge from the human LS (MMRd) phenotype. For example, murine models with constitutional homozygous MMR gene inactivation have high rates of lymphoma formation, limiting the efficacy of these models. In an effort to circumvent this challenge, investigators have employed tissuespecific Cre recombinase-based inactivation of MMR genes; however, these mice predominantly develop 
Lermi (2021)

tumors in the small intestine (as opposed to the large intestine in humans) (3). These limitations of cellular cultures and murine models warrant the need for better model systems to elucidate the intrinsic and extrinsic factors of MMRd carcinogenesis to help improve clinical outcomes for both LS and MSI

102 sporadic patients.

Given the anatomic and physiologic similarities and genomic homology between non-human primates

105 (NHPs) and humans, researchers have used several species of NHPs to develop therapies and vaccines to treat and eradicate human disease $(4,5)$. The rhesus macaque (Macaca mulatta), which shares $97.5 \%$

DNA sequence identity with humans in exons of protein-coding genes as well as close similarity in patterns of gene expression, has been an invaluable animal model for studying human pathophysiology (6, findings compared to other model organisms (8-11).

113 A cohort of specific pathogen free (SPF), Indian-origin rhesus macaques bred at The University of Texas

114 MD Anderson Cancer Center (MDACC) Michale E. Keeling Center for Comparative Medicine and

115 Research (KCCMR) spontaneously develops MSI/MMRd CRC, including a subset of animals harboring a 116 pathogenic germline mutation in $M L H 1$ (c.1029C<G, p.Tyr343Ter). This spontaneous mutation manifests

117 into clinical and pathological features similar to human LS, which suggests that these rhesus macaques 118 may be a superior model organism for studying MMRd CRC $(10,12)$.

120 This study characterized the genomic features of colorectal tumors in the KCCMR rhesus cohort using 121 microsatellite marker testing, whole transcriptomics, and epigenomics coupled with systems biology

122 tools, as illustrated in Figure 1. Additionally, we cross-compared the current subtypes of CRC in humans 123 with the rhesus model to evaluate the utility of rhesus for studying early cancer development, treatment 124 modalities, and prevention approaches in hereditary and sporadic CRC. 
Lermi (2021)

125

126

127

128

129

130

\section{Results}

Clinical characteristics of colorectal tumors in rhesus. We identified a total of 41 animals diagnosed with CRC at the time of necropsy. All tumors were located in the right side of the colon (20 in the ascending colon, 16 in the ileocecal valve, and 4 in the cecum) with the exception of one jejunal tumor. The mean age at death was 19.3 years (range: 9 and 27 years, Figure 2A) and $80 \%$ of animals were female (Figure 2B), consistent with overall population demographics of approximately $80 \%$ females from which the CRC animals were drawn. The average age at death was younger among the LS macaques than among the sporadic MSI macaques, but the difference is not statistically significant (17.75 vs 19.75 years, $P$-value $=0.3$, Figure $\mathbf{S 1}$ ).

\section{Germline Genetics}

We detected the presence of a previously described heterozygous germline stop codon mutation in exon 11 of MLH1 (c.1029C>G; p.Tyr343Ter, Figure 2C, Figure S2 and Table S1) in 8 animals ( 20\%) from KCCMR (10), thus confirming the presence of a causative pathogenic mutation of Lynch syndrome in humans (herein referred to as rhesus Lynch) (12). The remaining 33 animals (80\%) had the wild-type germline variant of $\mathrm{MLHI}$ (herein referred to as rhesus sporadic, Figure 2C).

\section{Immunohistochemistry (IHC) staining displayed widespread loss of expression in MLH1 and PMS2} in rhesus CRC. Of the rhesus CRCs with IHC data (n=37), 36 samples (97\%) had loss of MLH1 and/or PMS2 protein expression. Only one animal ( 3\%) retained the expression of the MLH1-PMS2 heterodimer. This same animal also displayed complete stability of the MSI markers, thus being MSS, and therefore, was considered MMR proficient. We subsequently used this animal as a control for all further genomic analyses (Figure 2D).

Assessment of MSI in rhesus CRC. We developed an MSI testing panel for rhesus CRC including orthologs of the most frequently used microsatellite markers in human CRC: BAT25, BAT26, BAT40, 
Lermi (2021)

D10S197, D18S58, D2S123, D17S250, D5S346, $\beta$-catenin, and TGF $\beta$ RII. Rhesus orthologs of D2S123,

presence of MSI. Hence, we excluded these markers from the rhesus MSI testing panel. Furthermore, the rhesus ortholog of BAT25 was not sensitive enough to determine MSI in rhesus CRC due to the interruption of the microsatellite by a nucleotide. Therefore, we substituted it with a novel MSI markerc-kitRheBAT25-identified through screening the whole sequence of the $c$-kit gene for an uninterrupted repeat region. Overall, the rhesus CRC MSI testing panel included 6 markers: 4 mononucleotide (ckitRheBAT25, RheBAT26, RheBAT40, RheTGFßRII) and 2 dinucleotide (RheD18S58, RheD10S197) markers (Table S1). This panel offers an assessment of the functionality of the MMR system in these rhesus macaques.

With the newly designed rhesus MSI panel, we performed MSI testing of tumors from the entire KCCMR cohort and used matched normal samples as a genomic reference $(n=41)$. c-kitRheBAT25, RheBAT26, 2F).

DNA methylation was responsible for developing CRC in the rhesus. As seen in human MSI CRC,

172 the phenotype of rhesus MSI-H CRC determined from MSI testing and transcriptomic profiling suggests 173 a vast majority of rhesus CRC may involve an epigenetic event. To determine the epigenetic contribution

174 to rhesus CRC, we analyzed the global DNA methylation patterns in tumor and normal samples.

175 Unsupervised principal component analysis (PCA) of reduced-representation bisulfite sequencing 176 (RRBS) data revealed clear clustering of MSI-H, MSI-L/MSS, and Lynch syndrome tumors, as well as 
Lermi (2021)

177

178

179

180

normal mucosa (Figure 3A). Hierarchical clustering of DNA methylation profiles using Pearson's correlation distance displayed a clear separation between rhesus tumor and matched normal tissue samples. Rhesus MSI-H tumor tissue samples clustered together with rhesus LS and separated from normal and rhesus MSS/MSI-L CRC (Figure 3B). Significant differentially methylated regions (DMRs) between rhesus normal and tumor tissue samples using a FDR of 5\% involved the following genes: TOP1, PCGF3, and FAM76B (hypermethylated), and $A L K B H 5, G A S 8$, and $M M E$ (hypomethylated, Figure 3C).

Lastly, we performed a dedicated methylation analysis of the $M L H 1$ promoter using a methyl NGS panel. Locations of $\mathrm{CpG}$ regions were shown from the transcription start site of the $M L H 1$ gene. Overall, thirteen $\mathrm{CpG}$ regions were significantly methylated in rhesus sporadic MSI-H tumor samples $(P$ value $<0.05)$ compared to adjacent normal mucosa. The majority of methylated $\mathrm{CpG}$ regions were located within exon 1 . There were no significant methylation differences between other tumor sub-groups and normal tissue samples (Figure S4); however, there was a clear trend of higher levels of $M L H 1$ promoter methylation among rhesus sporadic MSI-H compared to MSS tumors as well as a notorious absence of MLH1 methylation in the only LS tumor tested, which is consistent with human CRC biology.

\section{Gene expression patterns displayed differences between rhesus colorectal tumor and adjacent}

normal mucosa. Then, we performed whole transcriptome sequencing in 21 colorectal tumors and twenty matched normal mucosa samples. We had to exclude two tumors and four normal samples from downstream analysis due to low mapping efficiency. Unsupervised principal component analysis (PCA) of RNAseq data showed a clear separation of tumor and normal samples. However, samples from rhesus LS, rhesus sporadic MSI-H, and rhesus MSS/MSI-L clustered together without clear separation (Figure 4A). Additionally, to further characterize the rhesus LS animal model for studying human MSI-H colorectal cancer, we compared the similarity between rhesus LS tumor samples and human MSI-H and MSS colorectal tumors samples. The differential gene expression between The Cancer Genome Atlas 
Lermi (2021)

(TCGA) colorectal adenocarcinoma (COAD and READ, respectively) MSI-H tumor samples ( $\mathrm{n}=96)$ vs. the COADREAD MSS tumor samples group $(n=440)$ was analyzed by edgeR package. One hundred and one orthologous genes demonstrated statistically significant (BH-adjusted $P$-value $<0.05)$ changes in the expression level by at least two-fold $(\log 2 \mathrm{FC} \geq 1)$. Then we compared the spearman correlation between the rhesus Lynch tumor samples $(\mathrm{n}=21)$ and COADREAD MSI-H and MSS samples, while we used COADREAD normal $(n=54)$ and rhesus normal samples $(n=20)$ as control of species distance. The rhesus Lynch tumor samples have a larger correlation with COADREAD MSI-H tumor samples $(0.82)$ than that with COADREAD MSS samples (0.68) and normal samples (0.64, Figure 4B). This suggests that our analysis has sufficient resolution to compare different tumor tissue similarities.

We then determined significantly differentially expressed genes (DEGs) between rhesus normal and tumor by setting a Benjamini-Hochberg $(\mathrm{BH})$-adjusted $P$-value $\leq 0.05$ and $\log 2$ fold change \pm 1 . We annotated genes using human orthologs (Figure S5A). Unsupervised hierarchical clustering using DEGs demonstrated that rhesus tumor tissue samples clustered separately from normal tissue samples, and rhesus MSS/MSI-L CRC were separated from MSI-H CRC samples. Notably, animal RM17 displayed a

218 MSS phenotype despite carrying the $M L H 1$ germline mutation and clustered with the MSI-H group as opposed to the LS cohort (Figure 4D). Using the total RNAseq data, we sought to validate the expression of MMR genes using the counts of reads in tumors and matched normal samples. MLHI read counts in

221 MSI-High CRC samples were significantly decreased compared to normal tissue samples $(P$ -

222 value $<0.0001)$. As expected, animal RM02 with a MSS tumor showed more $M L H 1$ read counts in tumor

223 than matched normal (Figure S5B). MSH6 gene read counts in MSI-H CRC samples were significantly

224 more abundant than matched-normal samples $(P$-value<0.001). Differences of $M S H 2$ and $P M S 2$ gene

225 read counts between rhesus tumor and normal tissue samples were not significant. 
Lermi (2021)

We performed gene set enrichment analysis (GSEA) to discover relevant pathways in colorectal carcinogenesis of MSI-H and MSI-L/MSS rhesus CRC using the ESTIMATE algorithm, which assesses immune and stromal cell admixtures in tumors, canonical, immune, and metabolic pathways (Figure 5AC) $(14,15)$. When compared with normal tissue samples, the top observed pathways enriched in MSI-H tumor samples involved in cell cycle regulation, crypt base dynamics, and integrin signaling. Conversely, metabolic pathways in MSI-H samples were downregulated compared to normal tissue (Figure 5A). A similar trend was observed for MSS/MSI-L tumor samples compared to normal (Figure 5B). Lastly, comparing the significant pathways between MSS/MSI-L and MSI-H, we observed an upregulation of key pathways involved in cell cycle regulation and MYC targeting in the MSI-H group (Figure 5C).

CMS classification categorized rhesus CRC samples mainly as CMS2. We assigned a consensus molecular subtype (CMS) status to each tumor sample based on the nearest CMS probability (Table S3). Overall, 52\% $(\mathrm{n}=10)$ of tumors were classified as CMS2, which corresponds to the canonical pathways of colorectal carcinogenesis; $21 \%(\mathrm{n}=4)$ were CMS1, which progresses through MSI and immune pathways; and $21 \%(n=4)$ were CMS4, which develops through mesenchymal pathways. Only one tumor displayed mixed features (CMS1-CMS2) of a transition phenotype (Figures 5D).

\section{Rhesus CRC causes mutations in commonly mutated CRC genes. We examined somatic variants of} rhesus CRC using total RNAseq data. Our data indicated that the mutation rate of rhesus CRC is relatively high in all tested samples (Figure S6A). Commonly altered genes in human CRC were also mutated in rhesus such as APC, ARIDIA, TGBRII, TP53, CTNNB1, PIK3CA, KRAS (Figure S6B). Substitutions of cytosine to thymine were the most abundant in somatic variants of rhesus CRC (Figure S6C). Due to the close relation found in humans between MSI-H status and $B R A F$ mutations, we performed Sanger sequencing to assess the mutational status of the $B R A F$ mutation hotspot $V 600 E$ in rhesus CRC. While we did not detect BRAF V600E mutations among rhesus tumors, we did observe 
bioRxiv preprint doi: https://doi.org/10.1101/2021.08.19.456691; this version posted August 19, 2021. The copyright holder for this preprint (which was not certified by peer review) is the author/funder, who has granted bioRxiv a license to display the preprint in perpetuity. It is made available under aCC-BY-NC-ND 4.0 International license.

Lermi (2021)

252 different types of BRAF somatic variants including missense, nonsense, in-frame, and frameshift deletions

253 (Figure S7).

254 
Lermi (2021)

\section{Discussion}

Although cell cultures, organoids, and murine animal models are the most frequently used models in CRC research, these systems fail to recapitulate the phenotypic features of MMRd CRC, which limits clinical translation to humans. To overcome the differences between humans and research models, investigators have turned to NHPs due to their high degree of genomic and physiologic similarity to humans, including natural inter-individual genetic variation. Previous reports have proven rhesus macaques to serve as a durable and clinically-relevant animal model to study many infectious diseases and cancers $(9,10,16$, 17). In this study, our results from MSI testing, IHC, gene expression patterns, systems biology, somatic variant calling, and DNA methylation of colon tissue samples from the KCCMR cohort demonstrated that rhesus macaques develop CRC phenotypes analogous to MSI CRCs, including LS patients. These finding indicate that rhesus macaques may serve as an optimal animal model for studying MMRd CRC and addressing the shortcomings of previously-established model systems.

To characterize the rhesus macaque as a surrogate for studies of MMRd, we investigated the MSI status of 6 markers across 41 unique rhesus tumors using a newly designed, in-house MSI panel for rhesus CRC. Our study results indicated that $76 \%$ of rhesus CRC from the KCCMR cohort had a MSI-H phenotype, which warrants the use of rhesus as an optimal system to study MSI-H carcinogenesis. Many rhesus tumors lost expression of MLH1 and PMS2 proteins, but retained the expression of MSH2 and MSH6, as confirmed by IHC analysis. The $M L H 1$ germline stop codon mutation (c.1029C>G, p.Tyr343Ter), previously reported as a likely pathogenic variant in human LS (National Center for Biotechnology Information), was present in $8(19.5 \%)$ rhesus macaques, while the majority (80.5\%) were wild-type for this variant.

The DNA methylation analysis of rhesus CRC in this study suggests that epigenetics plays a pivotal role in rhesus CRC development. DNA methylation status of rhesus CRC using FFPE tissue samples from colon tumor and adjacent normal tissue samples indicated clear segregation of methylation patterns 
Lermi (2021)

281

282

283

284

285

286

287

288

289

290

291

292

293

294

295

296

297

298

299

300

301

302

303

304

305

306

between tumor/normal matches. Furthermore, based on analysis of the RRBS data, DNA methylation appears to play a major role as a driver of rhesus MSI CRC. Interestingly, although human CRC typically displays DNA methylation in the promoter region of the $M L H 1$ gene, methylation of rhesus CRC predominantly occurred in the exon1 region of $M L H 1$.

Despite prior reports of tissue-specific transcriptome analysis of fresh frozen tissues from rhesus macaques, to date, no study has analyzed the transcriptomic profile of colonic tissue from Indian origin rhesus macaques (18). Therefore, our study is the first transcriptomic analysis of matched tumor and normal colon samples in rhesus macaques, which provides essential information for the field of MMRdrelated research. Our transcriptomic data of rhesus CRC from FFPE tumor tissue displayed gene expression differences between rhesus tumor and normal tissue samples, and when compared to human TCGA MSI/MSS CRC data, rhesus MSI-H tumors were more similar to human MSI-H expression patterns than were human MSS tumors. These findings of transcriptomic homology between humans and rhesus support utilizing rhesus LS to study the carcinogenesis of MMRd CRC.

To confirm the biological relevance of the rhesus macaque as an animal model, we performed CMS classification and GSEA to ascertain the molecular features of rhesus MSI CRCs, including LS CRCs. Rhesus CRC from predominantly sporadic MSI-H and sporadic MSS/MSI-L mainly associated with CMS2 - the canonical subtype - which corresponds to SCNA high and WNT/MYC activation (14). However, rhesus LS tumors primarily associated with CMS1 (MSI-Immune), which aligns with previous studies from our group and encompasses MSI, CpG Island Methylator Phenotype (CIMP) high, hypermutation, immune infiltration, and worse overall survival after relapse (19). Conversely, most human sporadic adenomatous polyps typically cluster with CMS2, which was also observed for sporadic rhesus tumor samples. This observation is not entirely consistent with results for human CRC, but could reflect that the CMS classifier has been optimized to characterize human tumors and would require some degree of optimization in rhesus samples. 
Lermi (2021)

GSEA indicated activation of key pathways—namely cancer stem cell (CSC) signatures and crypt basein sporadic MSI rhesus CRC, which corroborates a previously described signature of human MMRd CRC (20). The pathway enrichment between MSI-L/MSS and MSI-H indicates that these advanced, late-stage lesions are transcriptomically similar, which may be driven by the late time point rather than MSI status.

312 These findings provide strong evidence to support the use of these rhesus macaques as a superior animal 313 model for understanding the molecular basis and TME of MSI CRC tumorigenesis.

315 To quantify the mutational rate in rhesus MMRd CRCs, we leveraged RNAseq data of rhesus LS tissues.

316 We acknowledge that this is not the most optimal way to analyze mutations but allowed us to observe high mutation rates in genes commonly mutated in CRC, independent of MSI status, thus adding additional support to the case for utilization of rhesus macaques for vaccine research, immunotherapy development, and biomarker studies for early detection screening.

321 We acknowledge that this study has several limitations necessitating further investigation. Importantly,

322 the comparator group, MMR proficient (MMRp) tumors, only included one rhesus, which challenged the

323 validity of the comparison between MMR proficiency and deficiency. Thus, a stronger comparator group

324 is necessary to strengthen our findings. Furthermore, this study lacks pertinent information regarding the

325 timeline of carcinogenesis for both sporadic and LS rhesus tumors, which restricts our understanding of

326 pre-cancer biology, and the timing of tumor development and evolution. Additionally, neoantigen

327 detection and T-cell receptor (TCR) profiling would be an important asset for a complete understanding

328 of the immune system in rhesus macaque CRC. Lastly, our mutation calling was performed using total

329 RNA sequencing data, which although adequate, is less ideal than whole exome sequencing.

331 In conclusion, this study provides a robust molecular and genetic characterization of a spontaneous and 332 translationally relevant NHP animal model useful for understanding MMRd CRC, including LS CRC. 
Lermi (2021)

333 These results justify the preclinical use of rhesus to study LS CRC and the larger group of sporadic MSI

334 CRCs. Unlike well-established murine animal models and ex-vivo cultures, the rhesus MMRd model

335 presented in this study, which occurs in an outbred species with inter-individual variation more

336 representative of the human condition than laboratory mice, affords the ability to test CRC prevention

337 strategies, assess TME dynamics, develop treatment modalities, and survey the immune landscape. 
Lermi (2021)

\section{Material and Methods}

Animal care. The rhesus macaque colony detailed in this manuscript was housed and maintained at

MDACC KCCMR in Bastrop, TX. The breeding colony of Indian-origin rhesus macaques (Macaca mulatta) at KCCMR is a closed breeding colony, which is specific pathogen free (SPF) for Macacine herpesvirus-1 (Herpes B), Simian retroviruses (SRV-1, SRV-2, SIV, and STLV-1), and Mycobacterium tuberculosis complex. All animal experiments were approved by the institutional animal care and use committee (IACUC) and the care of the animals was in accordance with institutional guidelines (IACUC protocol \#0804-RN02). Animal care and husbandry conformed to practices established by the Association for the Assessment and Accreditation of Laboratory Animal Care (AAALAC), The Guide for the Care and Use of Laboratory Animals, and the Animal Welfare Act. Tissue specimens from the proximal colon $(n=20)$, the ileocecal junction $(n=16)$, cecocolic junction $(n=2)$, cecum $(n=2)$, and jejunum $(n=1)$, as well as blood samples of rhesus macaques, were collected opportunistically at necropsy following euthanasia for clinical reasons. Formalin-fixed paraffin-embedded (FFPE) blocks and hematoxylin and eosin (H\&E) slides were prepared by veterinary pathology technicians and the diagnosis confirmed by veterinary

Nucleic acid extraction. Macro-dissection was performed to decrease the admixture of adjacent normal tissue and to enrich the percentage of tumor material for subsequent DNA and RNA extraction. Deparaffinization of FFPE tumor and adjacent normal specimens was performed using QIAGEN deparaffinization solution (QIAGEN, Valencia, CA). DNA and RNA from 19 tumor and adjacent normal samples was extracted using the AllPrep DNA/RNA FFPE Kit (QIAGEN) following the manufacturer's protocol. In the case of the unavailability of FFPE samples, genomic DNA and RNA were extracted from

360 fresh frozen tumor $(\mathrm{n}=2)$ and normal $(\mathrm{n}=3)$ samples using the ZR-Duet DNA/RNA MiniPrep extraction

361 kit (ZYMO RESEARCH, Irvine, CA). Quantification was performed with a NanoDrop One ${ }^{\mathrm{TM}}$

362 spectrophotometer (Thermo Fisher Scientific, Waltham, MA) and Qubit ${ }^{\text {TM }}$ Fluorometer 2.0 (Qubit, San 
Lermi (2021)

Francisco, CA) using dsDNA and RNA assay kits. RNA integrity was analyzed using the Tape Station RNA assay kit (Agilent Technologies, Santa Clara, CA).

Panel design for MSI testing. Commonly used human MSI markers (BAT25, BAT26, BAT40, D10S197, D18S58, D2S123, D17S250, D5S346, $\beta$-catenin, and TGF $\beta$ RII) were used as a reference to design a panel of rhesus MSI markers $(21,22)$. In brief, genomic positions of human MSI markers in the rhesus macaque genome (rheMac8) were identified using the batch coordinate conversion tool (liftOver) in the UCSC genome browser (23). Repeat patterns were compared to human MSI markers (Table S1). Orthologous microsatellite regions corresponding to human MSI markers D2S123, D17S250, and D5S346 were not specific to assess MSI in the rhesus genome. Therefore, they were excluded from the final MSI rhesus panel. Primer sequences to target identified microsatellite regions in rhesus were designed using the NCBI Primer Blast tool (Accession ID\# GCF_000772875.2) (24). The primer efficiency was evaluated using the UCSC Genome Browser In-Silico PCR tool (23) with rheMac8 as a reference control. The Baylor College of Medicine genome database was used to calculate the probability of encountering SNPs within the primer sequences. Primers sequences with allele frequency greater than $0.05 \%$ were redesigned (Table S2).

PCR-based MSI testing in rhesus CRC. Multiplex PCRs were designed with at least 25 bp size differences among PCR amplicons to afford clear distinction and identification on electropherograms from the Agilent Bioanalyzer 2100. All markers were amplified in $25 \mu \mathrm{l}$ PCR reactions using $12.5 \mu \mathrm{l}$ of AmpliTaq Gold ${ }^{\mathrm{TM}} 360$ PCR master mix (Thermo Fisher Scientific, Waltham, MA), corresponding primer sets, and 10 ng of FFPE DNA. Multiplex PCRs were performed in a Veriti 96 Well Thermal Cycler (Applied Biosystems ${ }^{\circledR}$, Foster City, CA) under the following cycling conditions: initial denaturation at $95^{\circ} \mathrm{C}$ for $10 \mathrm{~min}$, followed by 35 cycles at $95^{\circ} \mathrm{C}$ for $30 \mathrm{sec}, 55^{\circ} \mathrm{C}$ for $30 \mathrm{sec}$, and $72^{\circ} \mathrm{C}$ for $30 \mathrm{sec}$. A final extension at $70^{\circ} \mathrm{C}$ for 30 min was implemented to aid non-template adenine addition. Multiplex PCR products were resolved on a 5\% ethidium-bromide stained agarose gel. Multiplex PCRs were analyzed 
Lermi (2021)

via Agilent 2100 Bioanalyzer DNA 1000 kit (Agilent Technologies, Santa Clara, CA). Electropherograms

of adjacent normal and tumor tissue samples were compared to assess the status for each of the MSI

markers. Per NCI recommendations, MSI status was assigned by counting the number of unstable MSI

markers and samples were assigned to either: MSS (stable markers), MSI-L ( 1 unstable marker, $\leq 30 \%$ ),

or MSI-H (2 or more unstable markers, $(\geq 30 \%)(13)$.

MSI testing via fragment analysis for validation of the RheBAT26 and RheD18S58 markers. Fragment analysis (Applied Biosystems ${ }^{\circledR}$, Foster City, CA) was performed to validate MSI results from the Agilent sequences for RheBAT26 and RheD18S58 MSI markers was labeled with a 6-FAM fluorescent dye (Thermo Fisher Scientific, Waltham, MA). A multiplex PCR was designed to amplify RheBAT26 and RheD18S58 MSI markers with labeled primer sequences. PCR master mix and conditions were adopted from well-established PCR experiments. The fragment analysis method was performed by the Advanced Technology Genomics Core at MDACC. denaturation at $95^{\circ} \mathrm{C}$ for $10 \mathrm{~min}$, followed by 35 cycles at $95^{\circ} \mathrm{C}$ for $30 \mathrm{sec}, 55^{\circ} \mathrm{C}$ for $30 \mathrm{sec}$ and $72^{\circ} \mathrm{C}$ for $30 \mathrm{sec}$, with a final extension at $72^{\circ} \mathrm{C}$ for $7 \mathrm{~min}$. Purification of PCR products was performed with an inhouse ExoSAP solution [50 $\mu \mathrm{l}$ of Exonuclease I (20,000 units/ml) (NEB® M0568, Ipswich, MA); $40 \mu \mathrm{l}$

411 of Antarctic Phosphatase (5,000 units/ml); $16 \mu$ of Antarctic Phosphatase buffer (NEB® M0289S,

412 Ipswich, MA); $144 \mu \mathrm{l}$ of nuclease-free H2O]. PCR conditions for purification of PCR products were 413 incubation at $37^{\circ} \mathrm{C}$ for $15 \mathrm{~min}$ and at $80^{\circ} \mathrm{C}$ for $15 \mathrm{~min}$. Quality control of PCR products and purified PCR 414 products was performed running 1\% Agarose gel prepared with $25 \mathrm{ml}$ of $1 \mathrm{X}$ TBE buffer and $1.2 \mu \mathrm{l}$ of 
Lermi (2021)

415

416

417 lasergene software.

418

419

420

421

422

423 EpigenDx.

EtBr. Then, gel-purified PCR products were sequenced by the MDACC sequencing core (ATGC) via the Sanger Sequencing method. Analysis of Sanger sequencing data was performed using DNASTAR

Immunohistochemistry (IHC). Immunohistochemistry (IHC) staining for MLH1, MSH2, MSH6, and PMS2 was performed in FFPE tissue sections. Tissue sections were cut at $4 \mu \mathrm{m}$ and submitted to the MDACC Research Histology, Pathology, and Imaging Core (RHPI) in Smithville, TX. The following Agilent Dako IHC antibodies were used according to manufacturer's recommendations: IR079, Monoclonal Mouse Anti-human Mutl Protein Homolog 1, clone ES05 for MLH1; IR085, Monoclonal Mouse Anti-human Muts Protein Homolog 2, clone FE11 for MSH2; IR086 Monoclonal Rabbit Antihuman Muts Protein Homolog 6, clone EP49 for MSH6; IR087, Monoclonal Rabbit Anti-Human Posteiotic Segregation Increase 2, clone EPS1 for PMS2 (10).

Total RNA Sequencing. Truseq stranded total RNA library preparation kit (Illumina ${ }^{\circledR}$, San Diego, CA) was used to prepare libraries of 21 tumors and 20 matched normal RNA samples, which were extracted from FFPE and frozen tissue samples. Prepared libraries were sequenced for 76 nt paired-end sequencing on HiSeq ${ }^{\mathrm{TM}} 4000$ and NovaSeq6000 ${ }^{\mathrm{TM}}$ sequencers (Illumina ${ }^{\circledR}$, San Diego, CA).

Assessment of DNA methylation testing of MLH1. DNA methylation analysis of the $M L H 1$ gene was performed on DNA from frozen tissue samples of 7 tumors and 3 normal tissue (duodenum and blood) samples using a targeted NGS assay (EpigenDx, Hopkinton, MA). In brief, the bisulfite-treated DNA samples were used as a template for PCR to amplify a short amplicon of 300-500 bp using a set of primers that cover the $M L H 1$ genomic sequence at $-4 \mathrm{~kb}$ to $+1 \mathrm{~kb}$ from the transcriptional start site (TSS). 
Lermi (2021)

DNA methylation assessment via reduced representation bisulfite sequencing (RRBS). DNA libraries of

RRBS were constructed from FFPE tissue samples of 14 tumors/adjacent normal tissue pairs using the

Ovation RRBS Methyl-Seq System at The Epigenomics Profiling Core (EpiCore) of MDACC. In

444 preparation, DNA was digested with a restriction enzyme and selected for size based on established

445 protocols used in the EpiCore. Post-adapter ligation ensured enrichment for CpG islands, and DNA was

446 bisulfite-treated, amplified with universal primers, and qualified libraries were then sequenced on

447 Novaseq6000 ${ }^{\mathrm{TM}}$ and MiSeq sequencers at the UTMDACC ATGC.

Bioinformatics Analysis. The FASTQC toolkit was performed for quality control of FASTQ files generated from RNA sequencing (25). The fastp tool was performed to trim adapters and low-quality reads (26). Fasta and gtf files of the reference genome (Mmul_8.0.1) were downloaded from the Ensembl genome browser (27). The reference genome was indexed using the STAR RNA sequencing aligner. bisulfite mapper. The methylation information was extracted with bismark methylation extractor script. scores were excluded from downstream analyses. Count data per each sample generated by STAR RNA sequencing aligner was combined into one matrix for downstream bioinformatics analyses. Genes that have more than a sum of 100 reads in all samples were excluded from the analysis. The estimated read 
Lermi (2021)

Bioconductor R package (21, 29-31). MSI-L and MSS CRC cases were combined together based on previous human studies. Significant differentially expressed genes between MSI-H and MSS/MSI-L rhesus CRC were calculated using Benjamini-Hochberg (BH)-adjusted P-value $\leq 0.05$ and $\log 2$ fold change $\geq-1$ and $\log 2$ fold change $\leq 1$. Unsupervised hierarchical clustering was performed via Pearson's correlation. Comparisons of MMR gene counts between tumor and adjacent normal colorectal mucosa were performed using the DESeq2 Bioconductor R package. Complex heatmap and an enhanced volcano plot were created in R studio (version 3.6.1) (32). Rhesus Ensembl gene-IDs were converted to human Entrez ID for the CMS classification and GSEA. CMS classification of tumor samples was predicted using the random forest (RF) predictor in CMSclassifier R package (version 3.6.1) (14, 19). CMS classification was assigned to the subtype with the highest posterior probability. GSEA was performed with 1,000 permutations using CRC pathways with the fgsea $\mathrm{R}$ package $(14,33)$. CRC pathways included signatures of interest in CRC, the ESTIMATE algorithm that assesses immune and stromal cell admixture in tumor samples, canonical pathways, immune signatures, and metabolic pathways $(33,34)$.

Somatic and germline variant analyses of rhesus CRC samples were performed following GATK best practices. Filtered variants by Mutect 2 and Haplotypecaller tools of GATK were annotated with Variant Effect Predictor (VEP) (35). Mutation rates were calculated by dividing the number of non-synonymous somatic mutations by the number of callable bases.

Species comparison using TCGA datasets utilized raw RNA-Seq counts of MSI-H and MSS colorectal tumor samples and corresponding normal tissue samples (the 2016-01-28 analyses) of the TCGA project COADREAD and MSI status information was downloaded via FirebrowseR (version 1.1.35) package $(36,37)$. Then the raw data was filtered $(\min \cdot \operatorname{count}=10$, min.total $\cdot$ count $=15$, large $\cdot n=10$, min $\cdot$ prop $=$ 0.7) and normalized (TMM method) by package edgeR (version 3.32.1) (38). Genes showing statistically significant $(\mathrm{BH}$-adjusted p-value $<0.05)$ changes in the expression level by at least two-fold $(\log 2 \mathrm{FC}=1)$ between MSI-H and MSS samples were identified for the following analysis. The rhesus homologs were 
Lermi (2021)

494 (counts per million) of each in COADREAD MSI-H tumor tissues, COADREAD MSS tumor tissues,

495 COADREAD normal tissues, rhesus LS tumor tissues, and rhesus LS normal tissues were used to

496 calculate the Pearson's correlation of each group. CPM of each gene was used to perform the

497 unsupervised hierarchical clustering, and to generate the dendrogram tree and heat map for individual

498 samples.

499 For DNA methylation analysis of RRBS, PCA and sample clustering were performed using cytosine

500 report files in methylKit Bioconductor R package (35). The minimum coverage depth was 10 reads.

501 Differentially methylated regions (DMR) were calculated using bismark coverage report files with edgeR

502 Bioconductor R package (26). Significant DMRs at CpG loci were displayed at an FDR of 5\%.

503

504 Author's contributions

505 EV, SBG, JR, KMS conceived and supervised the study, and provided critical resources to perform the 506 experiments, and wrote the manuscript; NOL designed, performed the experiments, analyzed data, and 507 wrote the manuscript; NOL, RAH, MR and ND performed the analysis of RNA-sequencing data and 508 other bioinformatics analysis; CLH and MWT interpreted pathology slides; SBG and BKD provided the 509 animal model and specimens for analysis; FB genotyped the animals; CMB, LR-U, and KCM provided 510 assistance on the analysis and interpretation of the data, and writing and editorial assistance. All authors 511 critically read and intellectually contributed to the manuscript.

\section{Acknowledgements}

514 We acknowledge the support of Dr. Awdhesh Kalia at the School of Health Professions of MDACC for 515 providing access to the Agilent 2100 Bioanalyzer for MSI testing analysis. We acknowledge the support 516 of the Advanced Technology Genomics Core (ATGC) for performing the RNAseq, Sanger sequencing, 
bioRxiv preprint doi: https://doi.org/10.1101/2021.08.19.456691; this version posted August 19, 2021. The copyright holder for this preprint (which was not certified by peer review) is the author/funder, who has granted bioRxiv a license to display the preprint in perpetuity. It is made available under aCC-BY-NC-ND 4.0 International license.

Lermi (2021)

517 fragment analysis, and RRBS of this project; and Dr. Marcos R. Estecio for RRBS library preparation;

518 and support of the High-Performance Computing facility, which provided computational resources. 
Lermi (2021)

519

520

521

522

523

524

525

526

527

528

529

530

531

532

533

534

535

536

537

538

539

540

541

542

543

\section{References}

1. Siegel RL, Miller KD, Goding Sauer A, Fedewa SA, Butterly LF, Anderson JC, et al. Colorectal cancer statistics, 2020. CA Cancer J Clin. 2020;70(3):145-64.

2. Granat LM, Kambhampati O, Klosek S, Niedzwecki B, Parsa K, and Zhang D. The promises and challenges of patient-derived tumor organoids in drug development and precision oncology. Animal Model Exp Med. 2019;2(3):150-61.

3. McIntyre RE, Buczacki SJ, Arends MJ, and Adams DJ. Mouse models of colorectal cancer as preclinical models. Bioessays. 2015;37(8):909-20.

4. Phillips KA, Bales KL, Capitanio JP, Conley A, Czoty PW, t Hart BA, et al. Why primate models matter. Am J Primatol. 2014;76(9):801-27.

5. Brammer DW, Gillespie PJ, Tian M, Young D, Raveendran M, Williams LE, et al. MLH1rheMac hereditary nonpolyposis colorectal cancer syndrome in rhesus macaques. Proc Natl Acad Sci U S A. 2018;115(11):2806-11.

6. Bakken TE, Miller JA, Ding SL, Sunkin SM, Smith KA, Ng L, et al. A comprehensive transcriptional map of primate brain development. Nature. 2016;535(7612):367-75.

7. Rogers J, and Gibbs RA. Comparative primate genomics: emerging patterns of genome content and dynamics. Nat Rev Genet. 2014;15(5):347-59.

8. Friedman H, Haigwood N, Ator N, Newsome W, Allan JS, Golos TG, et al. The Critical Role of Nonhuman Primates in Medical Research - White Paper. Pathogens and Immunity. 2017;2(3):352-65.

9. Brewer M, Baze W, Hill L, Utzinger U, Wharton JT, Follen M, et al. Rhesus macaque model for ovarian cancer chemoprevention. Comp Med. 2001;51(5):424-9.

10. Dray BK, Raveendran M, Harris RA, Benavides F, Gray SB, Perez CJ, et al. Mismatch repair gene mutations lead to lynch syndrome colorectal cancer in rhesus macaques. Genes Cancer. 2018;9(3-4):142-52. 
Lermi (2021)

544 11. Harding JD. Genomic Tools for the Use of Nonhuman Primates in Translational Research. Ilar j.

545

546

547

548

549

550

551

552

553

554

555

556

557

558

559

560

561

562

563

564

565

566

567

568 2017;58(1):59-68.

12. National Center for Biotechnology Information A. https://www.ncbi.nlm.nih.gov/clinvar/variation/VCV000560781.1

13. Berg KD, Glaser CL, Thompson RE, Hamilton SR, Griffin CA, and Eshleman JR. Detection of microsatellite instability by fluorescence multiplex polymerase chain reaction. J Mol Diagn. 2000;2(1):20-8.

14. Guinney J, Dienstmann R, Wang X, de Reynies A, Schlicker A, Soneson C, et al. The consensus molecular subtypes of colorectal cancer. Nat Med. 2015;21(11):1350-6.

15. Yoshihara K, Shahmoradgoli M, Martínez E, Vegesna R, Kim H, Torres-Garcia W, et al. Inferring tumour purity and stromal and immune cell admixture from expression data. Nat Commun. 2013;4:2612.

16. Uno H, Alsum P, Zimbric ML, Houser WD, Thomson JA, and Kemnitz JW. Colon cancer in aged captive rhesus monkeys (Macaca mulatta). Am J Primatol. 1998;44(1):19-27.

17. Simmons HA. Age-Associated Pathology in Rhesus Macaques (Macaca mulatta). Vet Pathol. 2016;53(2):399-416.

18. Peng X, Thierry-Mieg J, Thierry-Mieg D, Nishida A, Pipes L, Bozinoski M, et al. Tissue-specific transcriptome sequencing analysis expands the non-human primate reference transcriptome resource (NHPRTR). Nucleic Acids Res. 2015;43(Database issue):D737-42.

19. Chang K, Willis JA, Reumers J, Taggart MW, San Lucas FA, Thirumurthi S, et al. Colorectal premalignancy is associated with consensus molecular subtypes 1 and 2. Ann Oncol. 2018;29(10):2061-7.

20. Bommi PV, Bowen CM, Reyes-Uribe L, Wu W, Katayama H, Rocha P, et al. The Transcriptomic Landscape of Mismatch Repair-Deficient Intestinal Stem Cells. Cancer Res. 2021;81(10):276073. 
Lermi (2021)

569 21. Boland CR, and Goel A. Microsatellite instability in colorectal cancer. Gastroenterology.

$570 \quad 2010 ; 138(6): 2073-87$ e3.

571 22. Schiemann U, Müller-Koch Y, Gross M, Daum J, Lohse P, Baretton G, et al. Extended

572 microsatellite analysis in microsatellite stable, MSH2 and MLH1 mutation-negative HNPCC

573 patients: genetic reclassification and correlation with clinical features. Digestion. 2004;69(3):166-

$574 \quad 76$.

575 23. Hinrichs AS, Karolchik D, Baertsch R, Barber GP, Bejerano G, Clawson H, et al. The UCSC

576 Genome Browser Database: update 2006. Nucleic Acids Res. 2006;34(Database issue):D590-8.

577 24. Ye J, Coulouris G, Zaretskaya I, Cutcutache I, Rozen S, and Madden TL. Primer-BLAST: a tool

578 to design target-specific primers for polymerase chain reaction. BMC Bioinformatics.

$579 \quad 2012 ; 13: 134$.

580 25. Andrews S. FastQC: A Quality Control Tool for High Throughput Sequence Data. 2010.

581 26. Chen S, Zhou Y, Chen Y, and Gu J. fastp: an ultra-fast all-in-one FASTQ preprocessor.

582 Bioinformatics. 2018;34(17):i884-i90.

583 27. Yates AD, Achuthan P, Akanni W, Allen J, Allen J, Alvarez-Jarreta J, et al. Ensembl 2020.

$584 \quad$ Nucleic Acids Res. 2020;48(D1):D682-d8.

585 28. Dobin A, Davis CA, Schlesinger F, Drenkow J, Zaleski C, Jha S, et al. STAR: ultrafast universal 586 RNA-seq aligner. Bioinformatics. 2013;29(1):15-21.

587 29. Love MI, Huber W, and Anders S. Moderated estimation of fold change and dispersion for RNA$588 \quad$ seq data with DESeq2. Genome Biol. 2014;15(12):550.

589 30. Baretti M, and Le DT. DNA mismatch repair in cancer. Pharmacol Ther. 2018;189:45-62.

590 31. Kawakami H, Zaanan A, and Sinicrope FA. Microsatellite instability testing and its role in the 591 management of colorectal cancer. Curr Treat Options Oncol. 2015;16(7):30.

592 32. Gu Z, Eils R, and Schlesner M. Complex heatmaps reveal patterns and correlations in 593 multidimensional genomic data. Bioinformatics. 2016;32(18):2847-9. 
Lermi (2021)

594 33. Sergushichev AA, Loboda AA, Jha AK, Vincent EE, Driggers EM, Jones RG, et al. GAM: a web-service for integrated transcriptional and metabolic network analysis. Nucleic Acids Res.

597 34. Yoshihara K, Shahmoradgoli M, Martinez E, Vegesna R, Kim H, Torres-Garcia W, et al. Inferring tumour purity and stromal and immune cell admixture from expression data. Nat

600 35. Akalin A, Kormaksson M, Li S, Garrett-Bakelman FE, Figueroa ME, Melnick A, et al. methylKit: a comprehensive R package for the analysis of genome-wide DNA methylation profiles. Genome Biol. 2012;13(10):R87.

603 36. Robinson MD, and Oshlack A. A scaling normalization method for differential expression analysis of RNA-seq data. Genome Biol. 2010;11(3):R25.

605 37. Deng M, Bragelmann J, Kryukov I, Saraiva-Agostinho N, and Perner S. FirebrowseR: an R client 606 to the Broad Institute's Firehose Pipeline. Database (Oxford). 2017;2017.

607 38. Robinson MD, McCarthy DJ, and Smyth GK. edgeR: a Bioconductor package for differential expression analysis of digital gene expression data. Bioinformatics. 2010;26(1):139-40.

609 39. Yates AD, Achuthan P, Akanni W, Allen J, Allen J, Alvarez-Jarreta J, et al. Ensembl 2020. Nucleic Acids Res. 2020;48(D1):D682-D8.

611 40. Durinck S, Moreau Y, Kasprzyk A, Davis S, De Moor B, Brazma A, et al. BioMart and Bioconductor: a powerful link between biological databases and microarray data analysis. Bioinformatics. 2005;21(16):3439-40.

614 41. Durinck S, Spellman PT, Birney E, and Huber W. Mapping identifiers for the integration of genomic datasets with the R/Bioconductor package biomaRt. Nat Protoc. 2009;4(8):1184-91. 
Lermi (2021)

618 Figure 1. Schematic outline of the experimental design. Sporadic and rhesus Lynch

619 (heterozygous $M L H 1$ nonsense mutation, c.1029, C>G) animals bred and housed at UTMDACC KCCMR

620 were used to genomically characterize colorectal tumors using an in-house MSI panel, IHC of MMR

621 proteins, epigenetic evaluation, whole transcriptomic analysis, and CMS classification. These analyses

622 establish the framework for utilizing rhesus as a surrogate to study MMRd CRC. UTMDACC KCCMR,

623 University of Texas MD Anderson Cancer Center Michale E. Keeling Center for Comparative Medicine

624 and Research; MSI, microsatellite instability; MMRd, mismatch-repair deficiency; CMS, consensus

625 molecular subtype; CRC, colorectal cancer.

626

Figure 2. Clinical, pathological, and molecular characteristics of the Rhesus cohort. (A) Animal ages at the time of diagnosis of CRC and subsequent euthanasia. The average age at death for the rhesus CRC cohort was 19.3 years. Red dots denote the age of animals with $M L H 1$ germline mutation; (B) Gender of KCCMR rhesus cohort. The majority of animals in this cohort were female; (C) Lynch syndrome MLH1 germline mutation status. Out of forty-one animals, eight (20\%) carried a heterozygous $M L H 1$ nonsense mutation (c.1029, C>G); (D) IHC assessment of rhesus CRC. The majority of tumor samples of rhesus testing panel for rhesus CRC included six markers (RheBAT25, RheBAT26, RheBAT40, RheD10S197, RheD18S58, and RheTGF $\beta$ RII) that were orthologs of commonly tested MSI loci in human tumors (BAT25, BAT26, BAT40, D10S197, D18S58, and TGFBRII). Overall, RheBAT25, RheBAT26, and RheD18S58 MSI markers were the most mutable MSI markers in rhesus CRC; (F) Summary of MSI 638 status of rhesus tumors. Rhesus CRC were predominantly MSI-H (75\%), and only six tumors (15\%) were 639 MSI-L, and four (10\%) MSS.

Figure 3. Methylation analysis of rhesus CRC. (A) PCA of DNA methylation in rhesus specimens 642 characterizing the trends exhibited by the differentially methylated region profiles of sporadic MSI-H 
Lermi (2021)

643 (green triangle), sporadic MSS and MSI-L (purple plus), Lynch syndrome (blue square), and normal

644 tissue (red circle) samples. Each shape represents a tissue sample type. Each group clustered separately;

645 (B) Hierarchical clustering of DNA methylation profiles assessed by CpG methylation using Pearson's

646 correlation. Distance displays the relationship between rhesus tumors and matched normal tissue samples

647 with parameters set as distance method: "correlation", clustering method: "ward"; (C) Significant

648 differentially methylated regions (DMRs) of rhesus normal and tumor samples at FDR of 5\%. TOP1,

$649 P C G F 3$ and $F A M 76 B$ were some of the hyper-methylated genes, and $G A S 8, A L K B H 5$ and $M M E$ were

650 hypo-methylated genes in rhesus CRC.

651

652 Figure 4. Transcriptomic analysis of rhesus CRC. (A) Principal component analysis (PCA) of rhesus

653 CRC showed the trends exhibited by the expression profiles of sporadic MSI-H samples (green triangles), sporadic MSS and MSI-L (blue squares), Lynch syndrome (red circles), and normal tissue (purple plus signs). Normal tissue samples clustered separately from tumor tissue samples; (B) Pearson's correlation coefficient of mean expression levels across 101 significant genes from COADREAD MSI-H tumor samples, COADREAD MSS tumor samples, COADREAD normal tissue samples, rhesus LS tumor samples, and rhesus normal tissue samples; (C) Significant differentially expressed genes (DEGs) 
bioRxiv preprint doi: https://doi.org/10.1101/2021.08.19.456691; this version posted August 19, 2021. The copyright holder for this preprint (which was not certified by peer review) is the author/funder, who has granted bioRxiv a license to display the preprint in perpetuity. It is made available under aCC-BY-NC-ND 4.0 International license.

Lermi (2021)

669 CMS2. The middle ring represents the MSI status of samples, and the inner ring indicates clinical 670 categories of samples. 
Figure 1

bioRxiv preprint doi: https://doi.org/10.1101/2021.08.19.456691; this version posted August 19, 2021. The copyright holder for this preprint (which was not certified by peer review) is the author/funder, who has granted bioRxiv a license to display the preprint in perpetuity. It is made available under aCC-BY-NC-ND 4.0 International license.

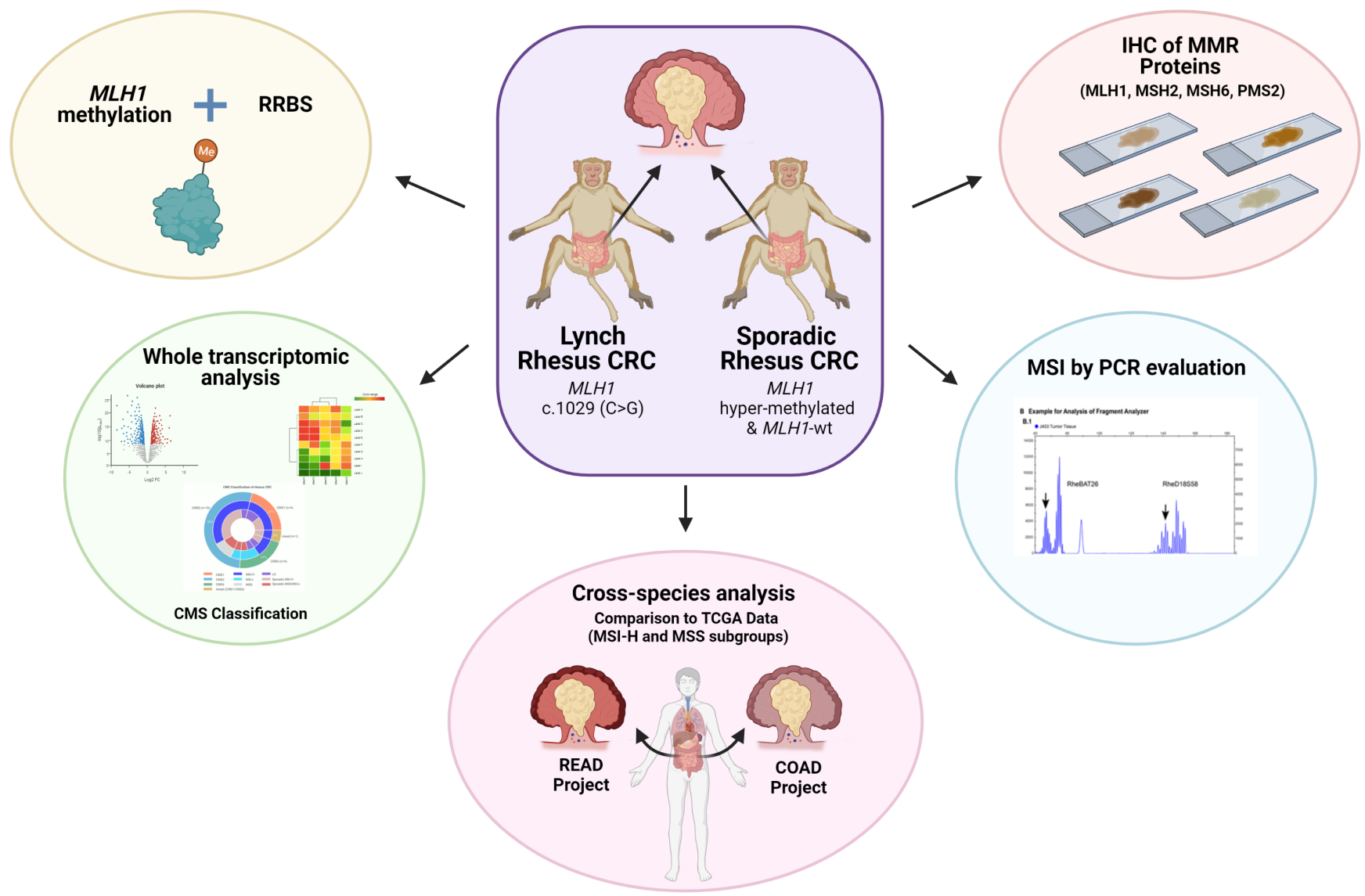

Figure 1. Schematic outline of the experimental design. Sporadic and rhesus Lynch (heterozygous MLH1 nonsense mutation, c. 1029, C>G) animals bred and housed at UTMDACC KCCMR were used to genomically characterize colorectal tumors using an in-house MSI panel, IHC of MMRd proteins, epigenetic evaluation, whole transcriptomic analysis, and CMS classification. These analyses establish the framework for utilizing rhesus as a surrogate to study MMRd CRC. UTMDACC KCCMR, University of Texas MD Anderson Cancer Center Michale E. Keeling Center for Comparative Medicine and Research; MSI, microsatellite instability; MMRd, mismatch-repair deficiency; CMS, consensus molecular subtype; CRC, colorectal cancer. 
Figure 2

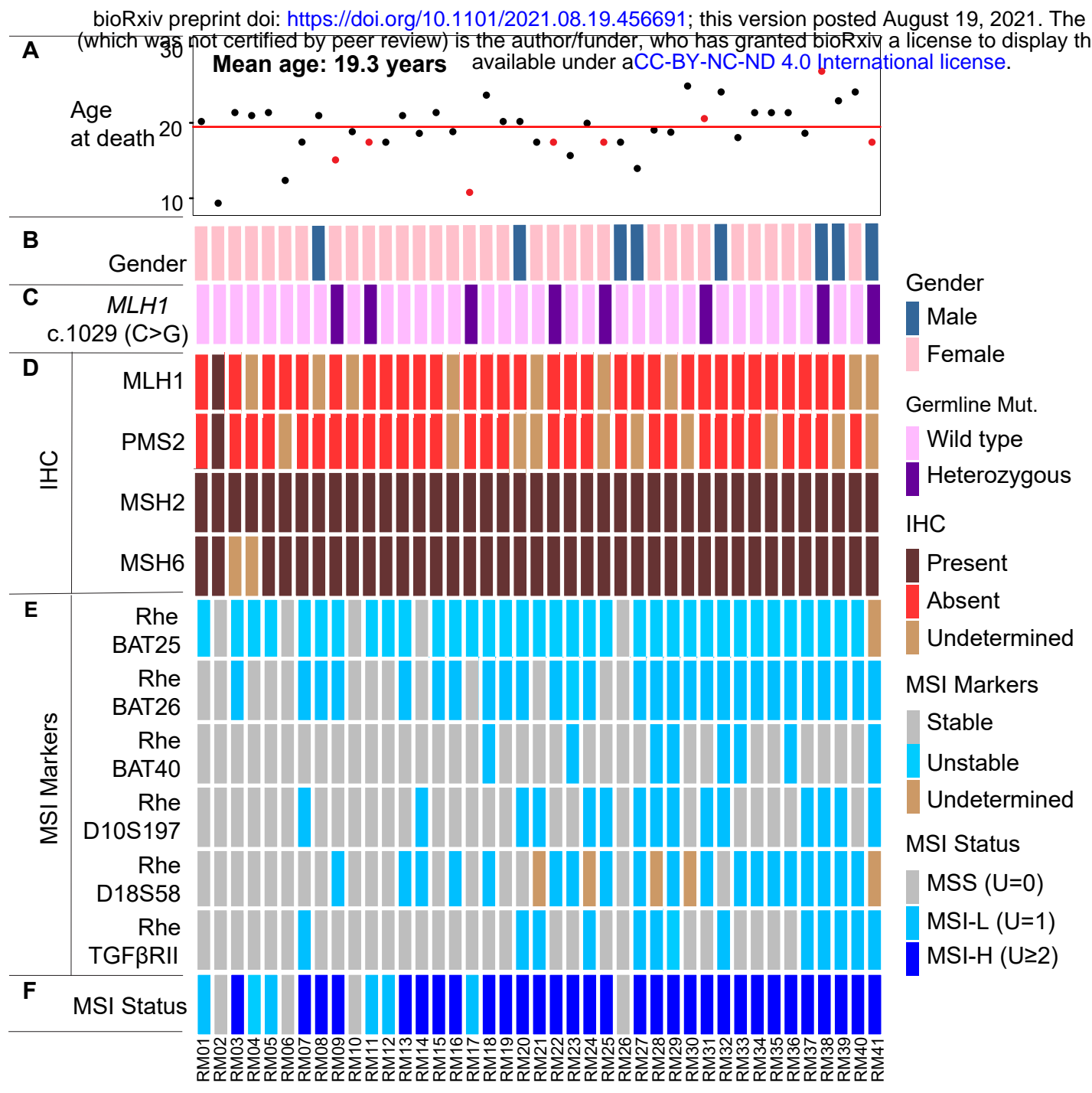

Figure 2. Clinical, pathological, and molecular characteristics of the Rhesus cohort. (A) Animal ages at the time of diagnosis of CRC and subsequent euthanasia. The average age at death for the rhesus CRC cohort was 19.3 years. Red dots demarcate age of animals with MLH1 germline mutation; (B) Gender of KCCMR rhesus cohort. The majority of animals in this cohort were female; (C) Lynch syndrome MLH1 germline mutation status. Out of forty-one animals, eight (20\%) carried a heterozygous MLH1 nonsense mutation (c.1029, C>G); (D) IHC assessment of rhesus CRC. The majority of tumor samples of rhesus CRC displayed loss of MLH1 and PMS2; (E) MSI testing of rhesus tumors. Newly designed MSI testing panel for rhesus CRC included six markers (RheBAT25, RheBAT26, RheBAT40, RheD10S197, RheD18S58, and RheTGF 3 RII) that were orthologs of commonly tested MSI loci in human tumors (BAT25, BAT26, BAT40, D10S197, D18S58, and TGFBRII). Overall, RheBAT25, RheBAT26, and RheD18S58 MSI markers were the most mutable MSI markers in rhesus CRC; (F) Summary of MSI status of rhesus tumors. Rhesus CRC were predominantly MSI-H $(75 \%)$, and only six tumors $(15 \%)$ were MSI-L, and four $(10 \%)$ MSS. 
Figure 3

bioRxiv preprint doi: https://doi.org/10.1101/2021.08.19.456691; this version posted August 19, 2021. The copyright holder for this preprint (which was not certified by peer review) is the author/funder, who has granted bioRxiv a license to display the preprint in perpetuity. It is made available under aCC-BY-NC-ND 4.0 International license.

A

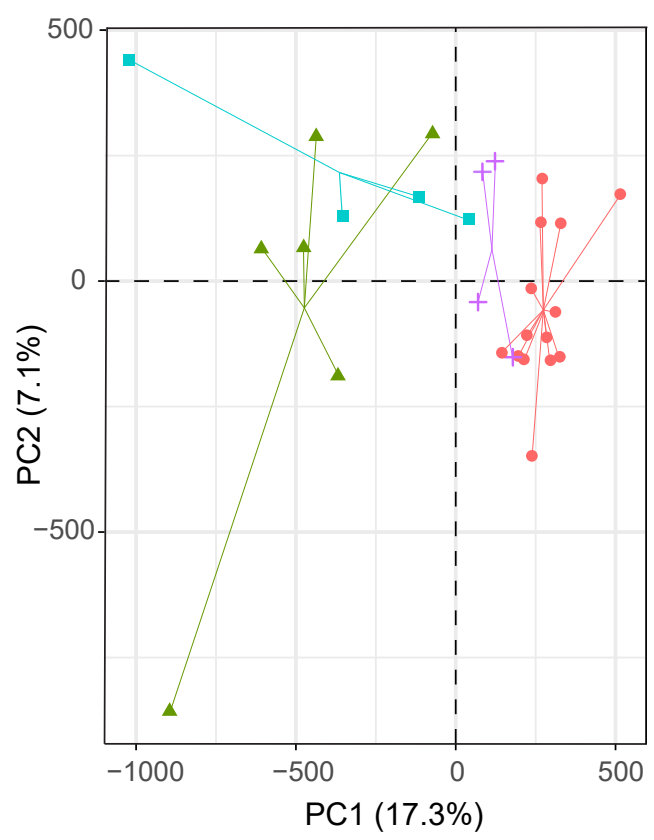

B

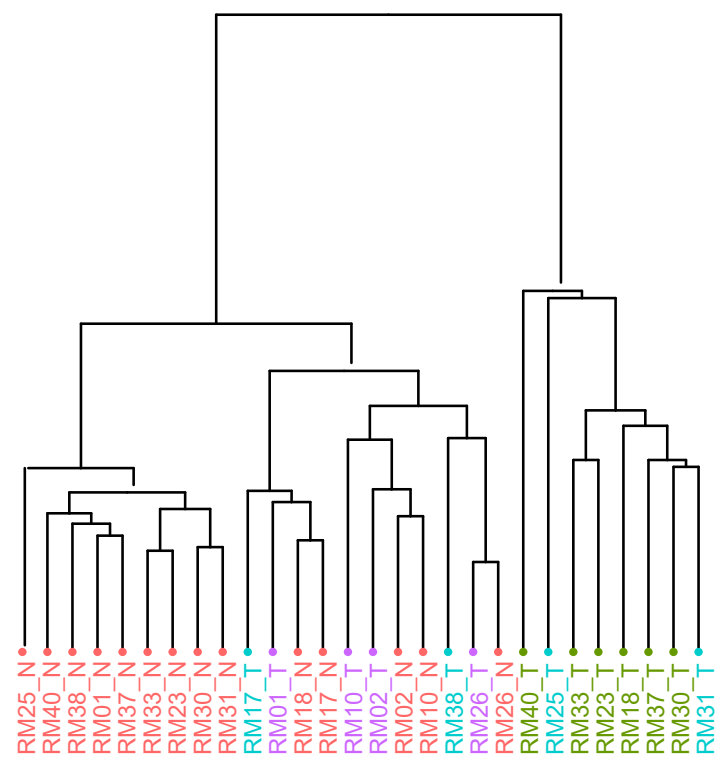

$\bullet \mathrm{LS} \bullet \mathrm{MSS} / \mathrm{MSI}-\mathrm{L} \bullet \mathrm{MSI}-\mathrm{H} \bullet \mathrm{Normal}$

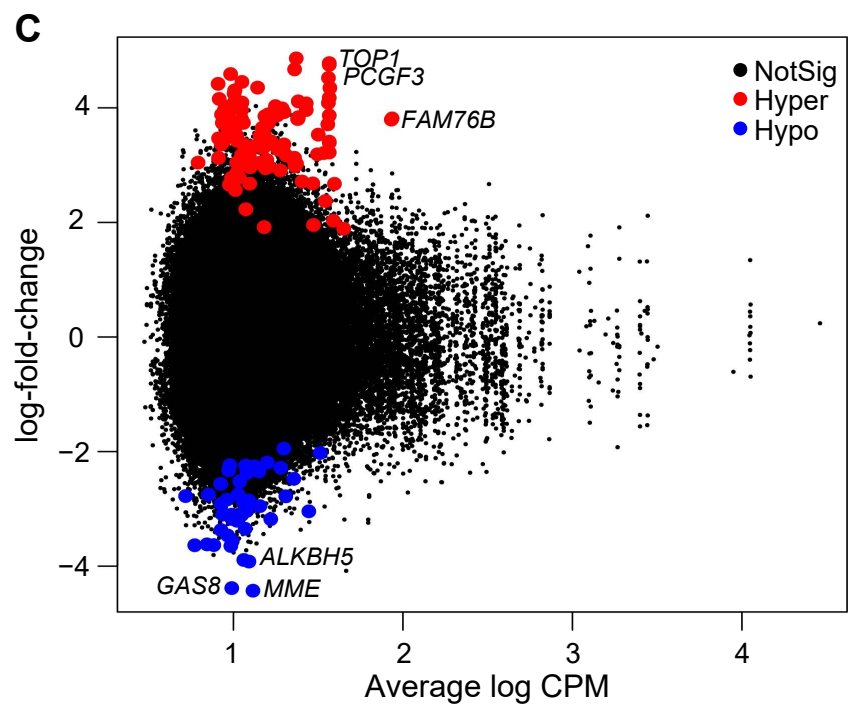

Figure 3. Methylation analysis of rhesus CRC. (A) PCA of DNA methylation in rhesus specimens characterizing the trends exhibited by the differentially methylated region profiles of sporadic $\mathrm{MSI}-\mathrm{H}$ (green triangle), sporadic MSS and MSI-L (purple plus), Lynch syndrome (blue square), and normal tissue (red circle) samples. Each shape represents a tissue sample type. Each group clustered separately; (B) Hierarchical clustering of DNA methylation profiles assessed by CpG methylation using Pearson's correlation. Distance displays the relationship between rhesus tumors and matched normal tissue samples with parameters set as distance method: "correlation", clustering method: "ward"; (C) Significant differentially methylated regions (DMRs) of rhesus normal and tumor samples at FDR of $5 \%$. TOP1, PCGF3 and FAM76B were some of the hyper-methylated genes, and GAS8, ALKBH5 and MME were hypo-methylated genes in rhesus CRC. 
Figure 4

A

bioRxiv preprint doi: https://doi.org/10.1101/2021.08.19.4691; this version posted August 19, 2021. The copyright holder for this preprint (which was notcertified by peer review) is the author/funder, who has granted bioRxiv a license to display the preprint in perpetuity. It is made
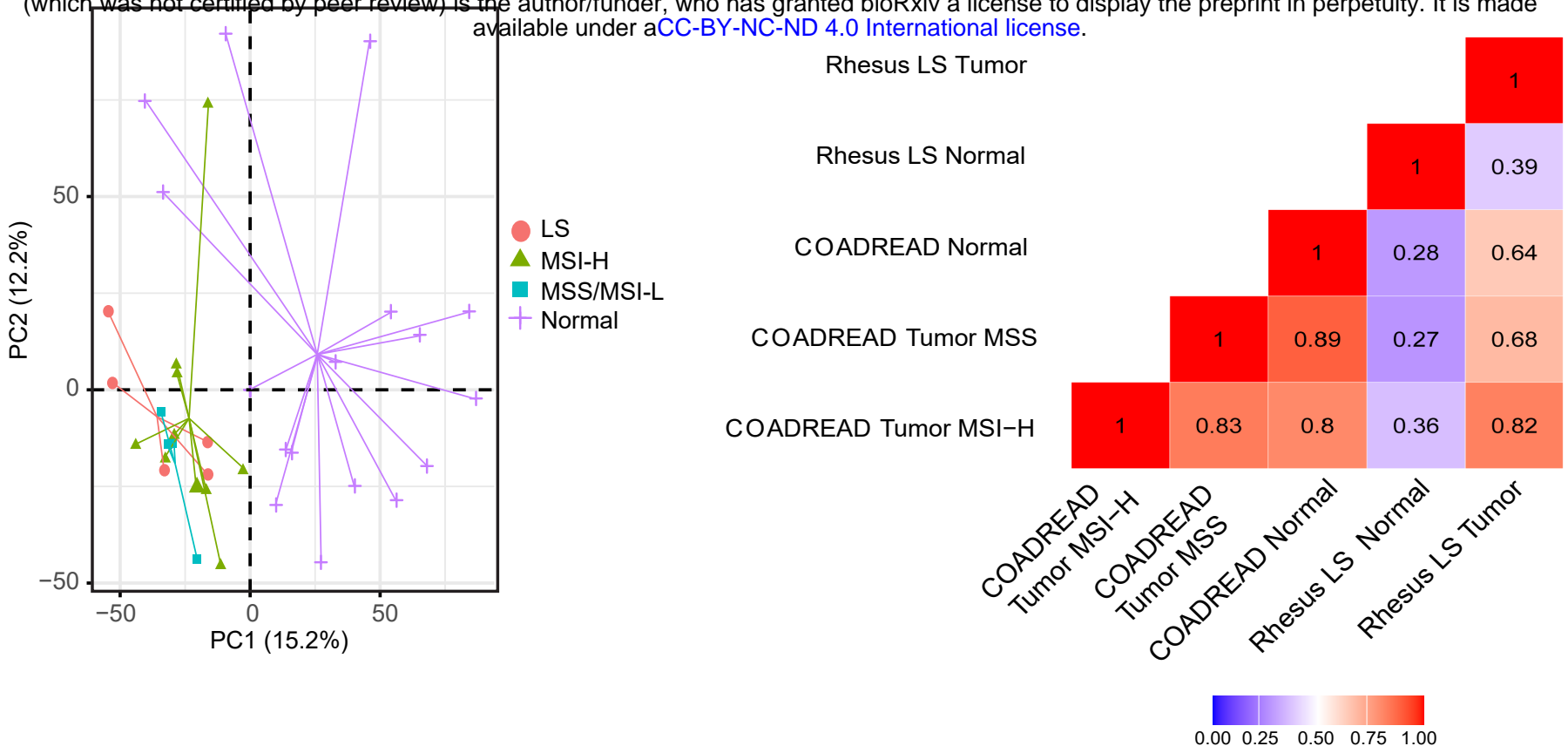

C

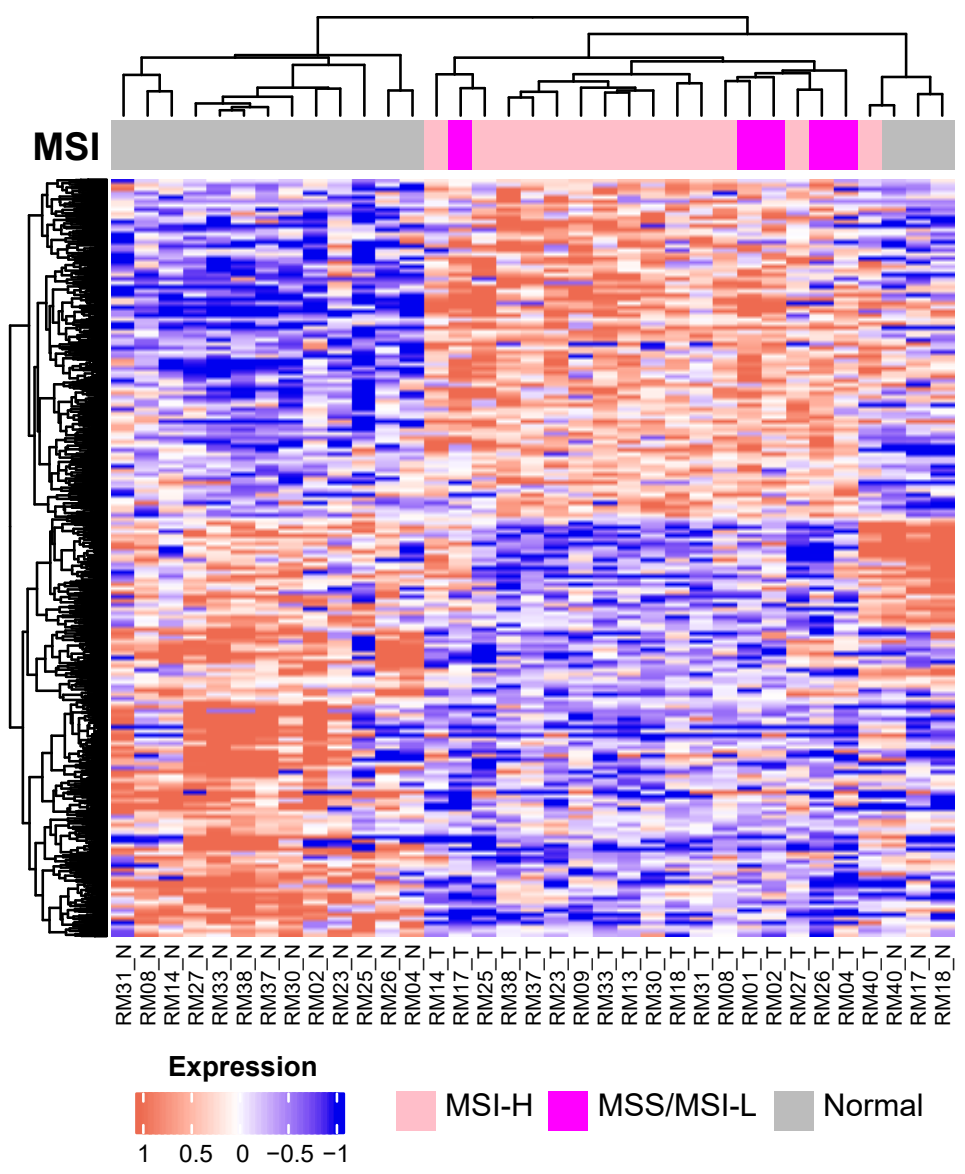

Figure 4. Transcriptomic analysis of rhesus CRC. (A) Principal component analysis (PCA) of rhesus CRC showed the trends exhibited by the expression profiles of sporadic MSI-H samples (green triangles), sporadic MSS and MSI-L (blue squares), Lynch syndrome (red circles), and normal tissue (purple plus signs). Normal tissue samples clustered separately from tumor tissue samples; (B) Pearson's correlation coefficient of mean expression levels across 101 significant genes from COADREAD MSI-H tumor samples, COADREAD MSS tumor samples, COADREAD normal tissue samples, rhesus LS tumor samples, and rhesus normal tissue samples ; (C) Significant differentially expressed genes (DEGs) between tumor and normal tissue samples. DEGs were found based on $\mathrm{BH}$-adjusted $P$-value $\leq 0.05$ between rhesus colorectal normal and tumor. Pearson's correlation was used to perform hierarchical clustering between rhesus tumor and normal tissue samples. Columns represent samples, and rows represent statistically significant differentially expressed genes. Gray color represents normal, pink MSI-H, and magenta MSS and MSI-L tissue samples. 


\section{Figure 5}

bioRxiv preprint doi: https://doi.org/10.1101/2021.08.19.456691; this version posted August 19, 2021. The copyright holder for this preprint (which was not certified by peer review) is the author/funder, who has granted bioRxiv a license to display the preprint in perpetuity. It is made available under aCC-BY-NC-ND 4.0 International license.

A

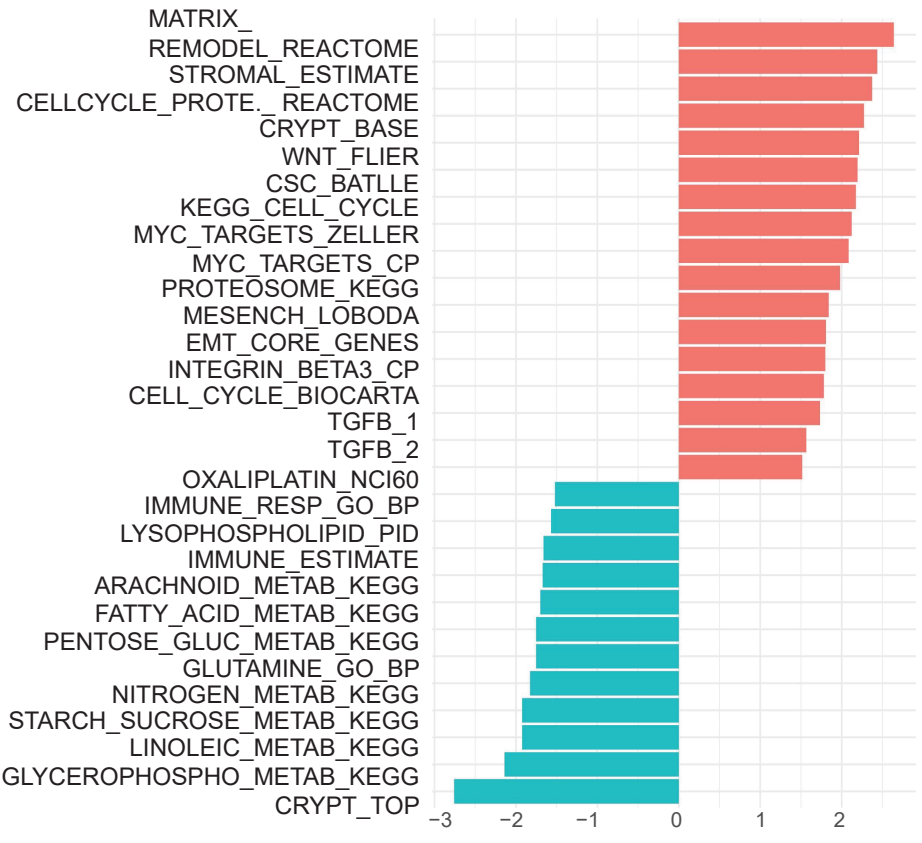

Down regulated in $\mathrm{MSI}-\mathrm{H}$ rhesus $\mathrm{CRC}$

Up regulated in $\mathrm{MSI}-\mathrm{H}$ rhesus $\mathrm{CRC}$
B

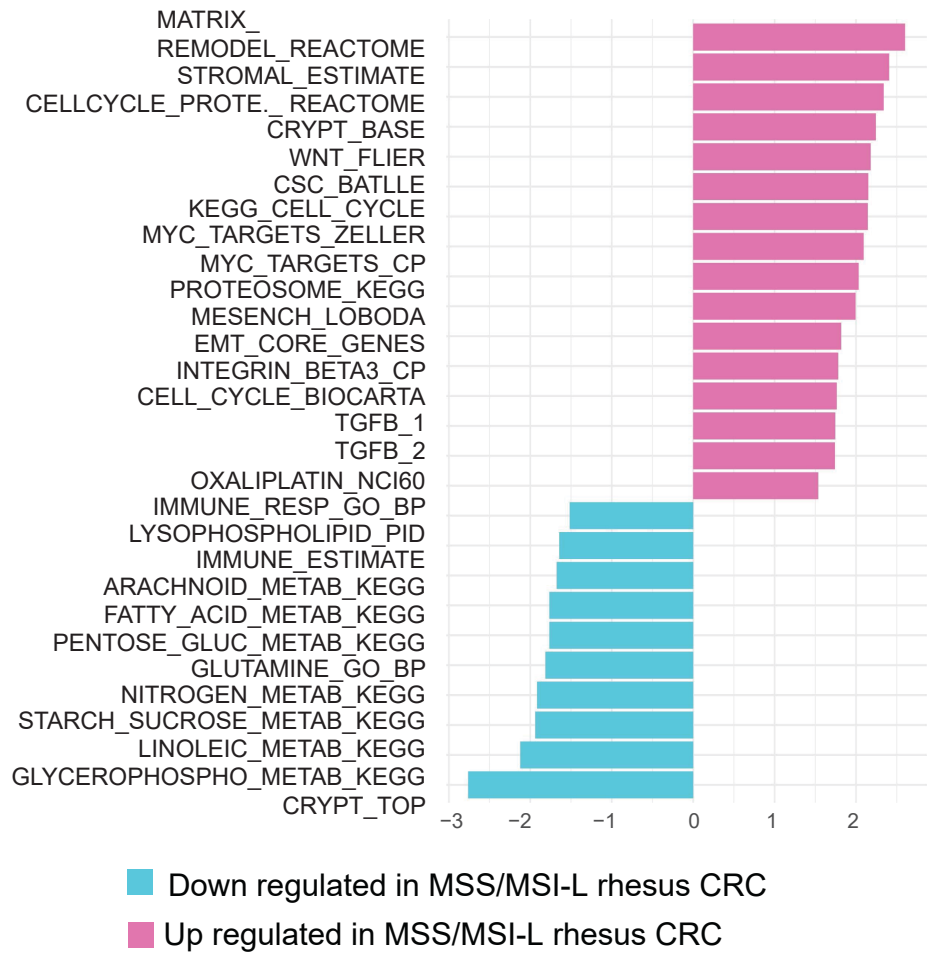

D

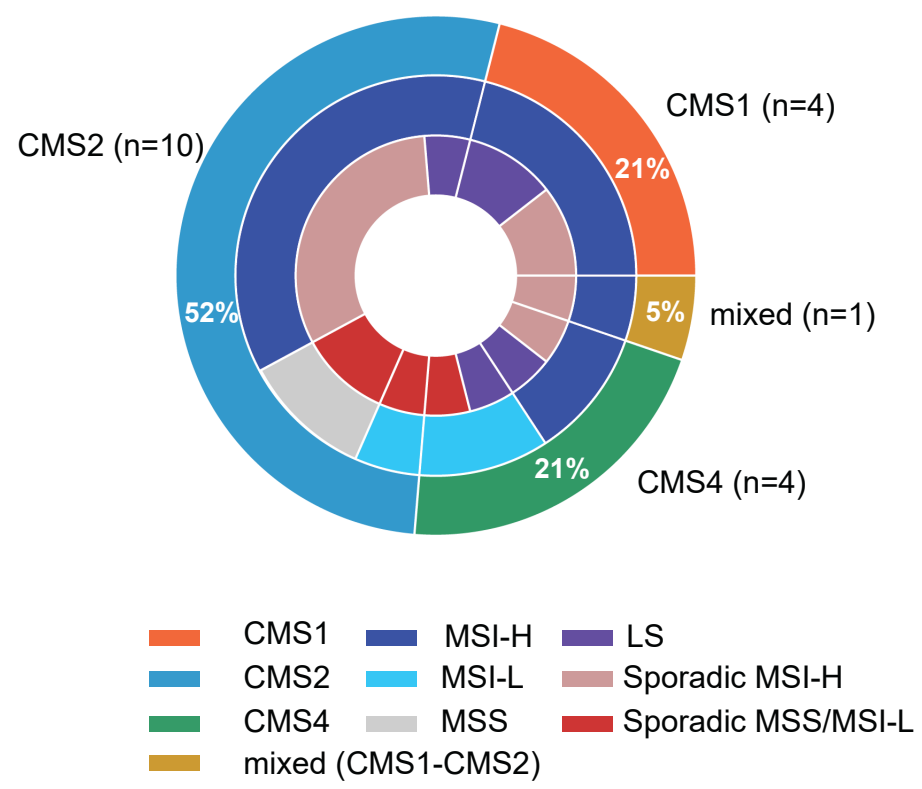
STROMAL ESTIMATE CRYPT BASE WNT FLIER CSC BATLLE KEGG_CELL_CYCLE C_TARḠETS Z̄ELLER MYC_TARGETS_CP 政H INTEGRIN BETA3 CP CELL CYCLE BIOCARTA TGFB_1

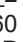
OXALIPLA ḠO BP IMMUNE_RESP_GO_BP IMMUNE_ESTIMATE ARACHNOID METAB KEGG OSE_GLUC_METAB KEGG GLUTAMINE GO BP

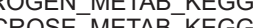
LINOLEIC METAB KEGG CRYPT TOP

Up regulated in MSS/MSI-L rhesus CRC EMT CORE GENES
CELL_CYCLE

PROTEASOME_REACTOME

MYC_TARGETS_ZELLER

PROTEASOME_KEGG

CELL_CYCLE_BIOCARTA

KEGG_CELL_CYCLE

TRANSLATION RIBOS_REACTOME

MYC_TARGET_CP

CRYPT_TOP

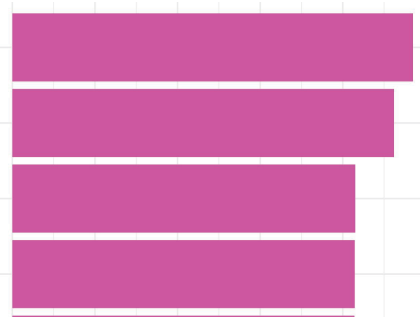

Up regulated in $\mathrm{MSI}-\mathrm{H}$ rhesus $\mathrm{CRC}$

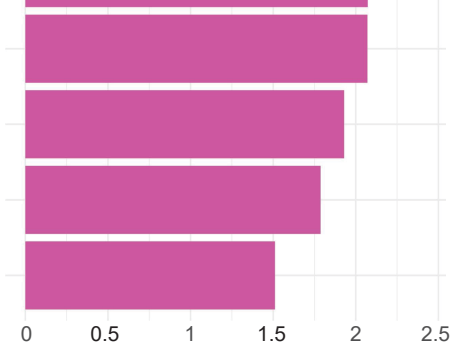

Figure 5. Gene set enrichment analysis in rhesus CRC. (A-C) Gene expression pathways are significantly deregulated in rhesus CRC. Pathways relevant to CRC biology are highlighted. BH-adjusted $P$-value $\leq 0.05$ was set as threshold for analysis; (D) CMS classification of rhesus CRC. The outer ring of circos plot represents CMS subtypes present in rhesus CRC with $52 \%$ of samples $(n=10)$ classifying as CMS2. Middle ring represents MSI status of samples, and inner ring indicates clinical categories of samples. 